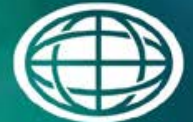

Savannah River

National Laboratory

OPERATED BY SAVANNAH RIVER NUCLEAR SOLUTIONS

Reductions without Regret:

Defining the Needed Capabilities

10 September 2013

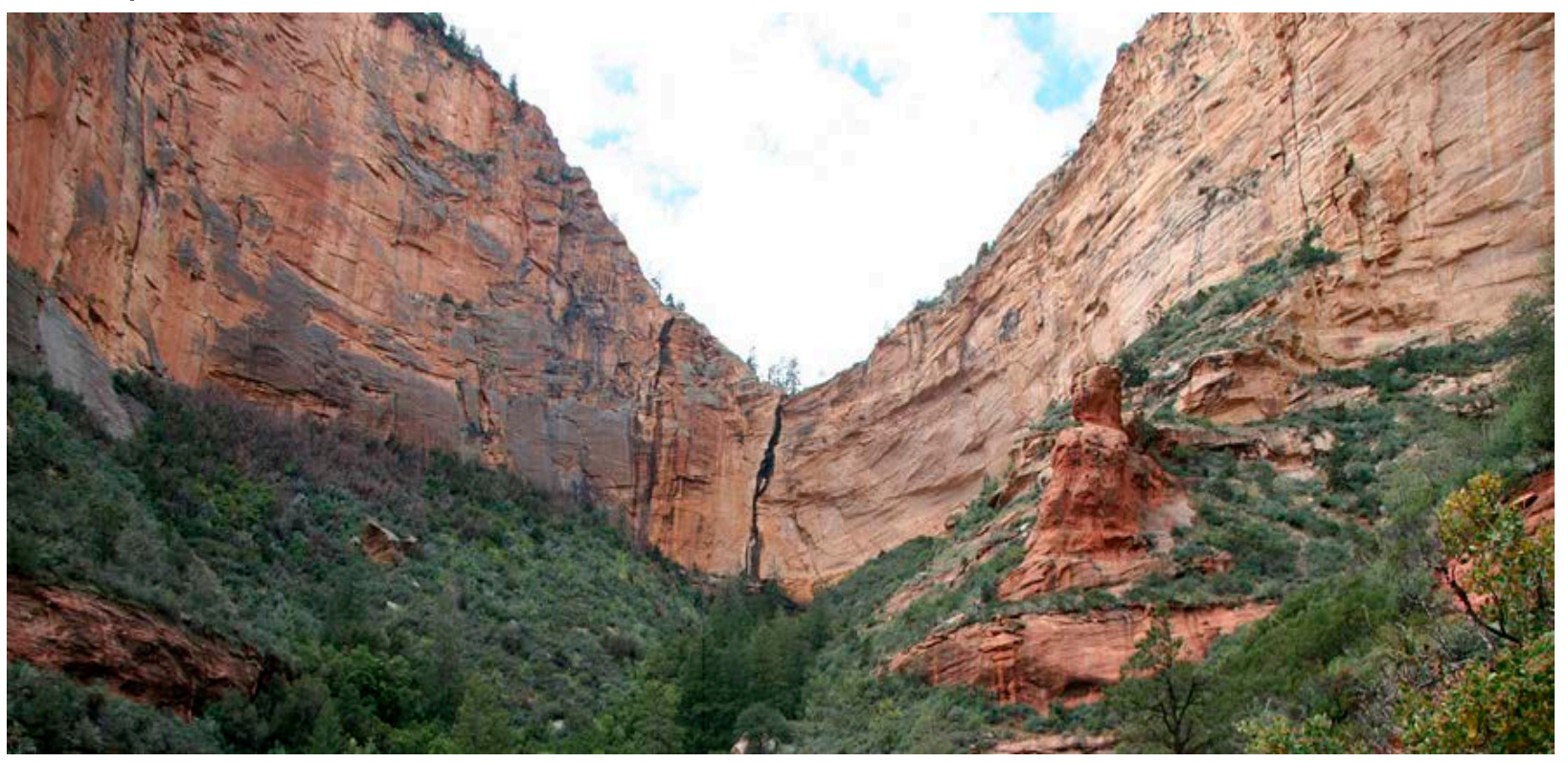

John A. Swegle

Douglas J. Tincher 
The analysis contained herein is that of the authors and does not reflect the views or positions of the Savannah River National Laboratory, the National Nuclear Security Administration, or the U.S. Department of Energy.

Savannah River National Laboratory

Aiken, SC 29808

John A. Swegle, 735-11A, Room 113, (803)725-3515

Douglas J. Tincher, 735A, Room B102, (803)725-4167 


\title{
Reductions without Regret: Defining the Needed Capabilities
}

\author{
John A. Swegle and Douglas J. Tincher \\ Savannah River National Laboratory
}

This is the second of three papers (in addition to an introductory summary) aimed at providing a framework for evaluating future reductions or modifications of the U.S. nuclear force, first by considering previous instances in which nuclear-force capabilities were eliminated; second by looking forward into at least the foreseeable future at the features of global and regional deterrence (recognizing that new weapon systems currently projected will have expected lifetimes stretching beyond our ability to predict the future); and third by providing examples of past or possible undesirable outcomes in the shaping of the future nuclear force, as well as some closing thoughts for the future.

This paper begins with a discussion of the current nuclear force and the plans and procurement programs for the modernization of that force. Current weapon systems and warheads were conceived and built decades ago, and procurement programs have begun for the modernization or replacement of major elements of the nuclear force: the heavy bomber, the air-launched cruise missile, the ICBMs, and the ballistic-missile submarines. In addition, the Nuclear Weapons Council has approved a new framework for nuclear-warhead life extension - not fully fleshed out yet - that aims to reduce the current number of nuclear explosives from seven to five, the so-called "3+2" vision. This vision includes three interoperable warheads for both ICBMs and SLBMs (thus eliminating one backup weapon) and two warheads for aircraft delivery (one gravity bomb and one cruise-missile, eliminating a second backup gravity bomb).

This paper also includes a discussion of the current and near-term nuclear-deterrence mission, both global and regional, and offers some observations on future of the strategic deterrence mission and the challenges of regional and extended nuclear deterrence.

\section{Current and Planned Nuclear Force}

Figure 1 outlines the current U.S. nuclear force:

- Minuteman III carrying either the W78 in the Mk-12A RV or the W87 in the Mk-21 RV;

- Trident D5 on the Ohio-class SSBN carrying either the W76 in the Mk-4 RV or the W88 in the Mk-5 RV;

- $\quad$ The Air-Launched Cruise Missile (ALCM, AGM-86B) carrying the W80 warhead, which is currently delivered by the B-52H bomber;

- The B83 gravity bomb, which can be delivered by the B-52H and B-2 bombers; and

- The B61 gravity bomb, delivered by the B-52H and B-2 heavy bombers, as well as the F16, F-15E, * and Tornado T-DCA; in the future, the F-35 is expected to take on the tactical delivery role.

\footnotetext{
* The long-term fate of the F-15E as a B-61 delivery system remains uncertain. The F-35 is claimed by the USAF as a replacement for the F-16; F-35 is not stated as a replacement for the F-15E. Apparently, if the AFRL's Adaptive Engine Technology Development program is fully successful, the USAF will need to
} 


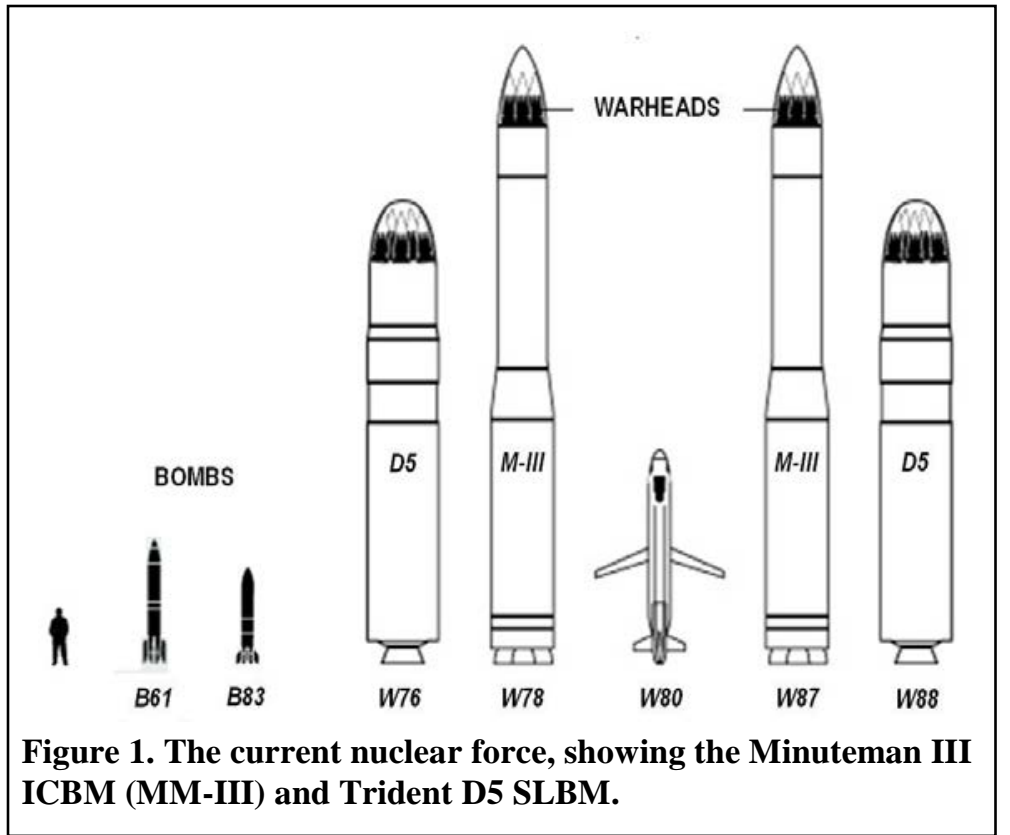

Figure 1. The current nuclear force, sho
ICBM (MM-III) and Trident D5 SLBM.
According to 2011 reporting from the General Accounting Office, ${ }^{1}$ the former GLCM warhead, the W84, remains in "managed retirement" status. With a modern design, the W84 is available for use if required.

The U.S. is in the process of modernizing the nuclear force, with a program that currently preserves the same basic force structure. As shown in Table 1, there are programs underway to replace the ALCM; the heavy bombers; the Ohio-class SSBN; and the Minuteman III ICBM.

\begin{tabular}{|c|c|c|c|}
\hline System & $\begin{array}{l}\text { Enter } \\
\text { Service }\end{array}$ & $\begin{array}{c}\text { Service } \\
\text { Life }\end{array}$ & Replacement \\
\hline B-52H & 1961-62 & $\sim 2040$ & Long Range Strike-Bomber (LRS-B) \\
\hline ALCM & 1982- & $\sim 2030$ & Long-Range Standoff (LRSO) \\
\hline W80 & 1982 & -- & Life extension or replacement with existing warhead* \\
\hline B61 & 1979-97 & $\sim 2050$ & Life extension \\
\hline B83 & 1983 & -- & To be determined \\
\hline B-2 (B61, B83, LRSO) & $1994-2000$ & $\sim 2060$ & Long Range Strike-Bomber (LRS-B) \\
\hline Minuteman III & 1970-78 & 2030 & To be determined \\
\hline W78 & 1979 & & Life extension \\
\hline W87 & 1986 & & Life extension \\
\hline Ohio-class SSBN & 1976-97 & 2031 & Ohio Replacement Submarine \\
\hline Trident II (D5) & 1990 & 2042 & Life extension \\
\hline W76 & 1978 & & Life extension \\
\hline W88 & 1989 & & Life extension \\
\hline Tactical air, F-16 (B61) & 1981 & $\sim 2020$ & F-35 \\
\hline Tactical air, F-15E (B61) & 1986 & $\sim 2030$ & To be determined \\
\hline
\end{tabular}

consider wholesale replacement of its current F-15E fleet with: new-manufacture F-15Es; a wholesale redesign of a two-seat, long-endurance variant of the F-35; or placing this mission in the LRS-B box. 
According to reporting of an April 2013 talk by Air Force Secretary Michael Donley, the next strategic bomber is being developed under the Long Range Strike-Bomber (LRS-B) program, with the goal of producing 80-100 bombers that will become operational in the mid-2020s. ${ }^{2}$ Although the bomber is expected to be manned originally, to date a capability for operating LRS-B unmanned is included in the program plan.

Department of Defense budgeting documents for fiscal year 2013 show that Long-Range Standoff (LRSO), the program to develop a successor to the ALCM, is proceeding with completion of the Analysis of Alternatives, a stage in the overall acquisition process. The same documents indicate that the Technology Development effort is to begin in 2015, with planned completion of that phase in 2017. ${ }^{3}$ Current planning is for the B-2 to carry the LRSO as well. ${ }^{4}$

A January 2013 Broad Agency Announcement (BAA) entitled “Ground Based Strategic Deterrence" solicited the preparation of white papers for "concepts that address modernization or replacement of the ground based leg of the nuclear triad." ${ }^{5}$ Beyond a baseline concept to retain the current Minuteman III system to 2075 with no plan to close capability gaps, the BAA outlines four additional concepts that are to be explored in the solicited white paper:

- $\quad$ Current Fixed Concept - Retaining the fixed-basing mode, modernize the Minuteman III "in the sub-component areas of guidance, propulsion, reentry vehicles/reentry systems, nuclear command, control and communications (NC3) and ground infrastructure.”

- $\quad$ New Fixed Concept - Develop a new, super-hard silo, and a new missile.

- $\quad$ Mobile Concept - Develop a new transporter erector launcher (TEL) for on- or off-road operation to carry and launch a new missile. The white paper is to consider the possibility that the missile could carry up to two Mk-12A or Mk-21 reentry vehicles.

- $\quad$ Tunnel Concept - Based in a subway-like tunnel with openings at regular intervals, a single new missile is to be carried on an unmanned transporter/launcher.

In all four cases, the white papers are to evaluate the MIRV capability of the missile, while the last three also require the evaluation of the adaptability of the missile to deliver Trajectory Shaping Vehicles / Trajectory Correcting Vehicles (TSV/TCV) for the reentry vehicle(s).

The progress of the Ohio replacement, or SSBN(X), program was described in a March 2013 report from the Congressional Research Service. ${ }^{6}$ This report states that the Navy intends to build 12 of the new SSBNs, in order to have 10 available at all times, since at any time, two are planned to be undergoing lengthy maintenance. Each submarine is planned to have 16 launch tubes, as opposed to the 20 active launch tubes currently available (of 24 originally installed) on Ohio-class SSBNs. The submarines are expected to have a 40-year lifetime, with no refueling of the nuclear reactors during that span. Roughly the same size as the current SSBNs, SSBN(X) will have quieter allelectric propulsion. Procurement of the first boat has been pushed back two years to 2021, the result of which will be that during the period 2029-2041, only 10 or 11 boats will be available, although the Navy states that none will be in maintenance during that period, so that the ten-boat criterion will be met.

The Fiscal Year 2014 Stockpile Stewardship and Management Plan for the Department of Energy outlines the directions for the life extension of existing warheads and a restructuring of the mix of nuclear explosives to be carried by the nuclear force. ${ }^{7}$ This restructuring would change the warhead assignments shown in Table 5, to varying degrees depending on the future implementation of the 
plan. Current directions from the Nuclear Weapons Council include life extension of the B61 (the Mod 12 version), completion of production of the W76-1, completion of the next phase of modernization of the W78/88-1, and downward adjustment of the mix of active and reserve status for the B83.

In the longer term, the Weapons Council has endorsed a " $3+2$ " vision for U.S. nuclear explosive systems that involves 3 missile-deliverable nuclear-explosive systems and 2 air-delivered systems; the intent is for each weapon type - missile- or air-deliverable - to be interoperable $e^{\dagger}$ across the delivery systems for its respective type (i.e., either ICBMs and SLBMs or cruise missiles and bombs). The first missile-deliverable Interoperable Warhead (IW-1) is to be a life-extended version of the W78/88-1. At this time, two additional such warheads, IW-2 and IW-3, have not been specifically determined, but the expectation is that they will be based on the W87/88 and W76-1.

\section{Looking Forward: The Nuclear Deterrence Missions}

According to the 2010 Nuclear Posture Review Report, ${ }^{8}$ we see that in a context in which the United States aims to reduce the role of nuclear weapons in U.S. national security strategy, the two major deterrence goals are to:

- Maintain strategic deterrence and stability at a reduced nuclear force level, condensing weapon variants and types, while reducing total numbers; eliminating weapons or weapon types if possible; and maximizing latent capability to replace critical systems; and

- Strengthen regional deterrence and reassure U.S. Allies and partners, shoring up posture and doctrinal statements ensuring confidence in U.S. deterrence.

For the foreseeable future, we anticipate that the nuclear deterrence mission will have global and regional aspects, as depicted in Figure 2.

- The five NPT Nuclear-Weapon States, shown in black in the figure, all have nuclear weapons with global reach.

- The NATO nations (in blue) reaffirmed in the 2010 Strategic Concept that NATO is a nuclear alliance. ${ }^{9}$

- The nations of the Middle East (in red) include those nations between Egypt in the west and Iran to the east, and the involvement of NATO state Turkey is significant as well.

- South Asia (in yellow) primarily involves India and Pakistan, although China is a factor in that dynamic, also.

- In the Western Pacific (in green), the U.S. participates in nuclear deterrence consultative bodies with Japan and South Korea, and Australia’s 2013 Defence White Paper continues the Australian policy of embracing U.S. extended nuclear deterrence. ${ }^{10}$ China, Russia, and North Korea are involved in the nuclear security dynamic of the Western Pacific. On the other hand, the nations of Southeast Asia are members of the Southeast Asian NuclearWeapon-Free Zone governed by the Treaty of Bangkok.

\footnotetext{
${ }^{\dagger}$ Interoperable warheads are defined in the 2014 Stockpile Stewardship plan as "warheads with a common [nuclear explosive package] integrated with non-nuclear systems that maximize the use of common and adaptable components," which are meant to be deployable on multiple delivery platforms.
} 


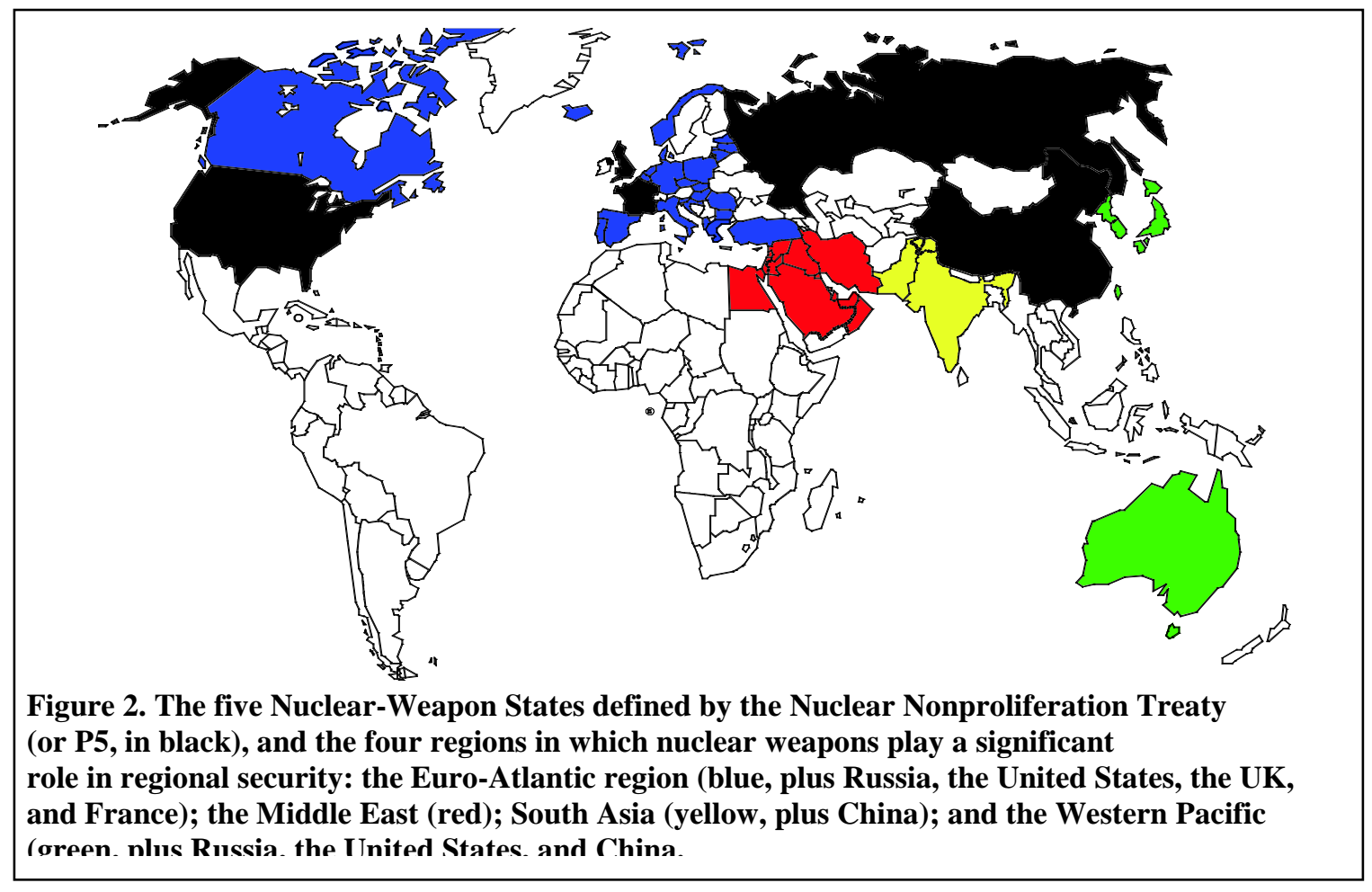

The nuclear capabilities of the declared nuclear nations are synopsized in Table 2. This table does not include Israel, which maintains official ambiguity about its nuclear status and does not discuss its delivery capabilities. Table 2 also does not include North Korea, which declares that it possesses the elements of a nuclear program, but has not demonstrated the integration of a nuclear weapon. In the absence of having apparently produced a nuclear weapon capability, Iran is also not on the table. Note that only the U.S. and Russia possess a full, intercontinental-range nuclear triad, although India is close to developing a regional nuclear triad with its soon-to-be-commissioned nuclear submarine and tests of an underwater-launched ballistic missile.

\begin{tabular}{|l|c|c|c|}
\hline & Land-Based Ballistic Missiles & Sub-Based Ballistic Missiles & Aircraft-Delivered \\
\hline United States & ICBM & Intercontinental & T-DCA, Strategic \\
\hline Russia & ICBM & Intercontinental & T-DCA, Strategic \\
\hline China & MRBM, IRBM, ICBM & Medium-range, Intercontinental & -- \\
\hline France & -- & Intercontinental & T-DCA \\
\hline United Kingdom & -- & Intercontinental & -- \\
\hline India & SRBM, MRBM, IRBM & Short-range & T-DCA \\
\hline Pakistan & SRBM, MRBM, IRBM & -- & T-DCA \\
\hline \multicolumn{2}{|l}{ Table 2. Delivery capabilities of the declared nuclear states } \\
\hline
\end{tabular}

In view of the circumstances, we sketch out the following current and expected strategic and regional nuclear deterrence missions, bearing in mind that the projected lifetimes for the strategic systems under development will stretch well beyond the foreseeable future:

- U.S.-Russia strategic - With the two largest nuclear forces comprised of the large majority of all nuclear weapons - in part a consequence of history, in part a reflection of the U.S. 
role in the world and Russia's position spanning most of the northern part of the Eurasian land mass - this deterrence relationship provides much of the motivation for each nation's nuclear triad. Although highly regulated and symmetrized by arms control agreements at the strategic nuclear end, other elements of the relationship - non-strategic nuclear weapons, missile defense, non-nuclear strategic capability, conventional military capability- remain much more asymmetric. ${ }^{11}$

- $\quad$ NATO/Euro-Atlantic regional - With three nuclear-weapon states in the alliance, NATO reaffirmed its commitment to nuclear deterrence in the 2010 Strategic Concept: "As long as nuclear weapons exist, NATO will remain a nuclear alliance.” For NATO, this includes collective nuclear defense planning and the concept of nuclear sharing, in which some non-nuclear members of the alliance are prepared to deliver U.S. nuclear weapons in time of war. Beyond the presence of Russian nuclear weapons in the region, Iran remains a potential threat on the periphery.

- U.S.-China strategic - This constitutes a mission for the U.S. triad and China's ICBMs and nascent submarine-borne deterrent. A highly asymmetric relationship, China has far fewer nuclear weapons, but theater-specific capability not matched by the U.S. and a developing anti-access/area-denial capability potentially affecting U.S. effectiveness regionally.

- Western Pacific extended - The U.S. has extended-deterrence relationships with Japan and South Korea, as well as substantial numbers of troops stationed in each country. In addition, as mentioned previously, Australia relies on the extension of nuclear deterrence by the U.S., and is preparing to host 2,500 U.S. Marines in the country. China possesses regional nuclear missiles, and North Korea possesses the elements of a nuclear force, regardless of its current ability to deliver nuclear weapons.

- $\quad$ Middle East regional - The U.S. has a strong alliance relationship with Israel, and should an Iranian nuclear threat become a reality, the U.S. role in the region could shift from dissuasion to deterrence, perhaps involving more formal extended-deterrence relationships with nations in the region if the proper constellation of alliances can be developed.

- $\quad$ South Asia regional - Although the United States has strong nonproliferation and nuclearsecurity concerns in South Asia, it does not have the same military alliance relationships and attendant nuclear-deterrence involvement in that region that it does elsewhere. Moreover, there are elements of resentment of the United States by both Pakistan and India that are exacerbated by mistrust of each other. ${ }^{12,13,14}$

\section{Observations on the Strategic Deterrence Mission}

The United States has entered a period in which the nuclear-deterrence mission is complicated not only by the increasingly multilateral nature of the problem, and the growing regionalization, but by the fact that recapitalization of the U.S. nuclear force is growing in urgency. Against this backdrop, we offer three observations on the strategic deterrence mission.

First, in the coming years, the cost of recapitalization and of maintenance and operation of the enduring force will be a major consideration, perhaps the major consideration. The current U.S. nuclear triad was conceived, designed, and built during the Cold War or in its immediate aftermath. It was formed, and its size was determined, by the bilateral strategic competition between two irreconcilable political-economic-social systems. Decision making was clearer cut under the circumstances, although even so, military decisions about the deployment of INF-range missiles or 
enhanced-radiation nuclear warheads (the so-called “neutron bomb”) were enormously controversial and the subject of election battles at the time for NATO allies.

For a variety of reasons, there has been a gap of some two to three decades in the development and deployment of new U.S. strategic nuclear systems. Other P5 states have moved past, or are moving through, this stage already:

- Although Russia was in a more precarious state when it was renegotiating the expiring START agreement, it has begun to move past that point, deploying new road-mobile missiles - with single or multiple warheads - commencing development of what could be a large liquid-fueled successor to the ten-warhead SS-18, ${ }^{15}$ completing development and beginning deployment of two new SLBMs (Liner and Bulava), and building the submarines to carry them.

- China continues to build and develop new nuclear weapon systems. In recent years, it has deployed the road-mobile DF-31A, capable of reaching much of the U.S., it has built and continues to build a new SSBN (Jin-class), it is completing development of the SLBM for that submarine, and it is apparently developing a new, road-mobile, multiple-warhead ICBM. $^{16}$

- France has four relatively new Triomphant-class SSBNs (commissioned between 1997 and 2010), it has developed a new nuclear warhead for its air-launched cruise missiles, and it will deploy a new nuclear warhead on the M51 SLBM currently under development and slated for deployment in 2015. ${ }^{17}$

- $\quad$ Although the U.K.'s nuclear deterrent force remains a subject of public debate, the 2006 document, The Future of the United Kingdom's Nuclear Deterrent, painted a clear picture: the current nuclear warhead would either be extended or replaced with a decision to be made in about 2025; the Trident D5 missile employed by the UK would be life extended, with a decision about possible replacement made in about 2035; and the process of replacing the Vanguard-class SSBNs, commissioned between 1993 and 1999, would begin in about 2025. ${ }^{18}$

In this context, with increasing complexity in the mission space, faced with the substantial cost of recapitalization, and constrained by U.S. budget realities, two points jump to the fore:

- Indecision born of complexity, and conflicted motivations created by the desire to reduce forces and the reliance on nuclear weapons, must be avoided if the United States is to prevent a reprise of the MX/Peacekeeper situation. There, an expensive, multiyear process played out when an escalatory, albeit technically superior, weapon system was developed as a match for the SS-18; then held hostage to repeated reviews of the same basing options; then compromised by the unpopular politics of the most effective mobile basing modes; and ultimately deployed in a strategically undesirable basing mode largely as a bargaining chip to motivate Soviet reductions in heavily-MIRVed missiles (a move ultimately defeated by evolving circumstances).

- If indeed the costs of force recapitalization are onerous, to what extent will the United States be able to use arms control measures to mitigate the burden, negotiating Russia down to numbers or force structures deemed more manageable on the U.S. end? And to what value, economically and in a political-military sense? Lastly, what strategies are available, and what compromises will be required?

Second, one must ask if, or at what point as the force is reduced, the triad becomes unviable. To be certain, the numbers of warheads are a major issue. To restate the obvious, we must ask at what 
force size it becomes impossible to maintain the nuclear triad at something greater than "critical mass?” Alternatively, are there a number of warheads at which a sort of "phase change” occurs in the constitution of the force? Finally, is there a supportable mix of nuclear- and conventionallyarmed strategic systems that mitigates the operational effects of nuclear reductions while satisfying the international political and strategic stability demands?

- Do unit costs, for construction, maintenance, and effective command and control rise to unjustifiable levels?

- With fewer, and smaller, units, do the military career paths become unattractive for our best officers? Will a combined strategic force of both nuclear- and conventionally-armed systems sustain those career paths?

Along a different line, the character of each element of the triad - ICBMs, SSBNs/SLBMs, and heavy bombers - depends essentially on the continued existence of the triad. Our understanding of that configuration was developed in the context of bilateral deterrence; however, in each of the three possible dyads, the role of each element changes in subtle ways. To take an example from history, the silo-based Peacekeeper, taken alone or perhaps as an element of a dyad with strategic bombers, created a strategic instability because of the unfavorable exchange rates for the defense (warheads lost to an attack versus the number of warheads required to attack successfully); however, the addition of survivable submarine-based missiles stabilized that situation.

The challenge of anticipating the issues in order to achieve an orderly reduction of the nuclear force raises two further questions:

- Is the United States prepared for the case in which it not only reduces strategic nuclear weapons, but in which it rolls strategic and non-strategic weapons together and places limits on the total?

- Viewing this last issue in a different way: What flexibility and scalability - downward, but if necessary, upward - are needed and do the available options provide? As an example, the 16-tube $\operatorname{SSBN}(\mathrm{X})$ represents smaller "steps" for force reduction than the 24-tube, or 20-tube, Ohio-class SSBN. Similarly, single-warhead ICBMs such as Midgetman scale downward more easily than heavily-MIRVed missiles, particularly as the numbers dwindle, but fail to provide upload capability for rapid upward scaling if that is required.

Third, we offer some specific thoughts for two elements of the triad. With regard to ICBMs, we note the following:

- The broader nuclear-deterrence role of ICBMs is clouded by the problem that purely ballistic missiles and RVs must overfly Russia to reach almost all targets of current interest. This complicates the deterrence challenge. As Schelling has pointed out, ${ }^{19}$ "Deterrence is concerned with the exploitation of potential force." The overflight issue raises a number of questions:

o Does the overflight issue create a threshold for U.S. ICBM launch, below which overflight is not worth the trouble?

o Will U.S. responses be delayed by a more complex decision-making process, and perhaps the need to warn Russia of impending overflight, or by the need to use SLBMs instead, which in many cases are slower to launch?

o Would a future U.S. administration feel the need to seek permission, making Russia a participant in the decision-making process? 
These questions all increase the uncertainty of U.S. nuclear use and thus degrade U.S. deterrent capability. This, of course, raises the issues of whether maneuvering warheads (or trajectory-shaping or trajectory-correcting vehicles) could be used, or if perhaps boosters can be developed to fly non-minimum-energy trajectories in order to inject ballistic RVs into non-overflight trajectories. In either case, the challenge is to find the means by which the available non-overflight target set can be expanded. Otherwise, the United States will be faced with the issue of addressing the overflight of Russia to employ ICBMs in a deterrence role against potential targets in the Western Pacific and the Middle East.

- Have potential adversaries' advances in accuracy, for the yields available, made different basing modes than current silos necessary? Are there future scenarios in which mobile ICBMs would be necessary to assure survivability and strategic stability, particularly at lower numbers, and what features of those scenarios dictate mobility?

- Does the U.S. wish to retain some upload capability, even if only in maintaining a reserve margin in the throw weight of the boosters?

- Ultimately, beyond the rapid response that ICBMs can provide, ICBMs enhance deterrence by dispersing and increasing the nuclear target set presented to a U.S. adversary, a point made by Keith Payne in 2012 Congressional testimony. ${ }^{20}$ Drawing on analysis by Johnson, Bowie, and Haffa, ${ }^{21}$ Payne pointed out that eliminating ICBMs in favor of a nuclear dyad of SSBNs and B-2 bombers reduced the number of aim points to five (two submarine bases and three bomber bases) from five plus the number of missile silos (which is now 450).

With regard to SLBMs, the following points stand out:

- In launching SLBMs, SSBNs identify their location, at least for a time. Given the expected lifetimes for the next generation of SSBNs, this raises the question of whether planners must anticipate a future in which long-endurance armed drones are deployed to provide top-cover for submarine launches, or, alternatively, are deployed in an anti-submarine role to defend against SLBM launches.

- What are the arguments for and against two-ocean basing of SSBNs?

- Should the U.S. build 8, 10, or 12 Ohio replacement submarines, and should each have 16 or 20 launch tubes, as discussed by Woolf? ${ }^{22}$

- What is the associated scalability of our SSBN force downward under reductions and upward as a hedge?

\section{Observations on the Challenges of Regional and Extended Deterrence}

As the complexity of regional and extended deterrence grows, drawing in part from the 2010 Nuclear Posture Review Report, it appears that within the constraints of the current nuclear force, there are three elements to regional deterrence:

- Enhanced consultation with allies and partners;

- Regional deployment of heavy bombers and T-DCA; and

- Use of "strategic" systems in "tactical" roles.

NATO has a history of consultation in support of its nuclear-sharing arrangement, primarily through the Nuclear Planning Group. ${ }^{23}$ In Northeast Asia, following the announcement of the elimination of TLAM/N, strengthened consultation was established with South Korea in late 2010 
via the U.S.-ROK Extended Deterrence Policy Committee, and with Japan in 2011 via the U.S.Japan Extended Deterrence Dialogue.

Regional deployment outside the U.S. and NATO is a serious challenge. The Presidential Nuclear Initiatives in 1991 and 1992 eliminated nuclear basing in South Korea, and made temporary regional basing of non-strategic nuclear weapons on aircraft carriers and attack submarines unlikely under peacetime conditions. Elimination of TLAM/N finally eliminated the sea-based nuclear cruise missile option, following earlier elimination of carrier basing.

In-theater basing of nuclear weapons in the Western Pacific is complicated by a number of factors:

- In Japan, repeatedly reaffirmed national policy has limited or prevented "introduction" of foreign nuclear weapons;

- Australia, although the beneficiary of extended nuclear deterrence, is a signatory of the Treaty of Rarotonga and a member of the South Pacific Nuclear-Weapon-Free Zone; and

- Although North Korea has arguably invalidated the treaty, South Korea is nevertheless a party to the 1992 Joint Declaration of South and North Korea on the Denuclearization of the Korean Peninsula.

To illustrate the challenges of regional basing, consider Table 3, which shows distances from three nominal basing locations, Guam, the British territory of Diego Garcia, and the air base at Aviano, Italy. Guam, of course, is U.S. territory; however, as indicated in the table, ranges from Anderson Air Force Base to Northeast Asia are substantial. Region deployment of heavy bombers is logistically complicated if an "air bridge” of refueling tankers is required, although B-52 $\mathrm{s}^{24}$ and B$2 \mathrm{~s}^{25}$ recently provided a demonstration of U.S. extended deterrence capability in South Korea.

Temporary basing in-theater would presumably require the existence of adequately safe and secure nuclear facilities at Anderson AFB.

\begin{tabular}{|l|c|l|c|l|c|}
\hline $\begin{array}{c}\text { From Guam } \\
\text { to: }\end{array}$ & $\begin{array}{c}\text { Distance } \\
\mathbf{( k m )}\end{array}$ & $\begin{array}{c}\text { From Diego } \\
\text { Garcia to: }\end{array}$ & $\begin{array}{c}\text { Distance } \\
\mathbf{( k m )}\end{array}$ & $\begin{array}{c}\text { From Aviano } \\
\text { AB to: }\end{array}$ & $\begin{array}{c}\text { Distance } \\
(\mathbf{k m})\end{array}$ \\
\hline Beijing & 4,000 & Abu Dhabi & 3,900 & Abu Dhabi & 4,400 \\
\hline Hanoi & 4,200 & Bandar Abbas & 4,100 & Bandar Abbas & 4,400 \\
\hline Manila & 2,550 & Colombo & 4,000 & Cairo & 2,400 \\
\hline Pyongyang & 3,400 & Islamabad & 4,400 & Damascus & 2,400 \\
\hline Quanzhou & 3,000 & Karachi & 3,500 & Kiev & 1,400 \\
\hline Seoul & 3,200 & Kolkota & 3,700 & Minsk & 1,400 \\
\hline Shanghai & 3,100 & Muscat & 3,600 & Moscow & 2,100 \\
\hline Shenzen & 3,400 & New Delhi & 4,000 & Riyadh & 3,800 \\
\hline Singapore & 4,700 & Riyadh & 4,500 & St. Petersburg & 1,900 \\
\hline Tokyo & 2,500 & Singapore & 3,600 & Tehran & 3,400 \\
\hline \multicolumn{7}{|l|}{ Yangon } & 5,200 & Tehran & 5,200 & Tel Aviv & 2,400 \\
\hline $\begin{array}{l}\text { Table 3. Distances between example points for a hypothetical consideration of medium- } \\
\text { and intermediate-range missile basing. }\end{array}$
\end{tabular}


The Middle East presents similar challenges. Referring back to Table 3, one can see that the British territory of Diego Garcia is at least as far from the Middle East as Guam is from Northeast Asia. The NATO airbase at Aviano, on the other hand, is much closer. More to the point, though, the U.S. still has not established the same extended deterrence relationships in that region that exist in the Euro-Atlantic and Western Pacific regions.

From a deterrence standpoint, given the lack of a U.S. non-strategic nuclear weapon other than TDCA armed with B61 gravity bombs, and given the possession of more non-strategic nuclear options by Russia and China, one can reasonably ask whether the totality of U.S. nucleardeterrence options are credible, sufficient, and appropriate to the regional missions of:

- $\quad$ Phase-0 deterrence; ${ }^{26}$

- Assurance, and reassurance, of allies and partners; and

- Escalation control, from crisis through to conflict.

Under current circumstances, U.S. deterrence and, if necessary, escalation control, will depend in large measure on the employment of "strategic" nuclear weapons in a "regional" role. We close this paper by raising three issues about this "crossover" role for strategic nuclear weapons (see the following text box). We will address these in the next paper. First, we suggest that there are

\section{Regional, or Non-Strategic, vs Strategic Nuclear Weapons: Is a Nuke a Nuke?}

Although this is a topic deserving of more discussion, let us briefly sketch out some of the parameters that affect the deterrent, or military, significance of nuclear weapons. We can intuitively grasp the difference between strategic nuclear weapons, with global destructive reach, and regional or nonstrategic weapons with shorter range and, in some cases, more specialized use (e.g., a nuclear torpedo). The manner in which they are, or would be, employed is also significant: offensively, defensively, or perhaps in the case of a country like Iran or North Korea, non-traditionally (colloquially, the "nuclear car bomb," delivered in a non-attributable fashion). Where is significant: in-country or extra-territorial use. Considering the combination of the manner and the location, clearly offensive use extra-territorially is far more threatening and escalatory than defensive use in-country, for example. Yield should make a difference, but perhaps less on first use than in multiple-use situations; and perhaps not much beyond high and low from the standpoint of the signal sent (where the fog of war would be expected to be significant in a conflict), although yield is much more significant from the standpoint of calculated military requirements.

The nature of the correspondents in a deterrence relationship is highly significant, too. Strategic depth is important: big-sponge countries such as the United States, Russia, and China have a much different strategic calculus, and present a different picture to potential adversaries, than shallow-depth countries such as Israel, Pakistan, or even a Japan. Relative strength of conventional military forces plays a role; intuitively it seems that the possession of non-strategic weapons in addition to conventional superiority is more threatening than the possession of such weapons by a conventionally inferior nation.

Indeed, in regard to this last point, considerable discussion has been devoted in recent years to the question of whether or not conventional weapons can assume certain deterrent roles currently filled by nuclear weapons. ${ }^{1}$ We suspect that the deterrent capability of conventional weapons, in comparison to a nuclear option, depends at least as much on the conventional superiority or inferiority of the nations involved as it does on the weapons themselves. Indeed, in this regard, perhaps a certain "natural selection" has already been at work in the earlier elimination of some U.S. nuclear capabilities.

1. For example, see Michael S. Gerson, Conventional Deterrence in the Second Nuclear Age, Parameters, p. 32, Autumn 2009. 
intrinsically different features for limited and demonstrably regional nuclear capabilities distinguished by range, penetrability, yield, or numbers - that send a usefully different message. Second, we expect that the fog of war can, under some circumstances, obscure the difference between "tactical" and "strategic" weapons. Third, given that there is a need for regional nuclear deterrence, the alternative to non-strategic nuclear weapons will be dual-capable strategic nuclear systems (e.g., a low-yield SLBM warhead) or a T-DCA-deliverable modification of LRSO.

\section{References}

1 GAO, Nuclear Weapons: DOD and NNSA Need to Better Manage Scope of Future Refurbishments and Risks to Maintaining U.S. Commitments to NATO, May 2011, GAO-11-387.

2 Dave Majumdar, USAF leader confirms manned decision for new bomber, 23 April 2013, available from the Flight Global website, http://www.flightglobal.com/news/articles/usaf-leader-confirms-manneddecision-for-new-bomber-385037/.

3 PE 0604932F: LONG RANGE STANDOFF WEAPON, available from http://www.dtic.mil/descriptivesum/Y2013/AirForce/stamped/0604932F_5_PB_2013.pdf.

4 LT GEN James M. Kowalski, Status of Air Force Strategic and Nuclear Systems, Department of the Air Force, Presentation to the Senate Armed Services Committee, Strategic Forces Subcommittee, April 17, 2013, available from the website of the Senate Armed Services Committee, http://www.armedservices.senate.gov/statemnt/2013/04\%20April/Kowalski_04-17-13.pdf

5 Broad Agency Announcement (BAA), US Air Force Nuclear Weapons Center (AFNWC), Program Development and Integration Directorate (AFNWC/XZ) Ground Based Strategic Deterrence, 7 January 2013, BAA-AFNWC-XZ-13-001, available from https://www.fbo.gov/?tab=documents\&tabmode=form\&subtab=core\&tabid=2d5eec29c02d7efc3649e8fb e54ecc75.

6 Ronald O’Rourke, Navy Ohio Replacement (SSBN[X]) Ballistic Missile Submarine Program: Background and Issues for Congress, March 14, 2013, Congressional Research Service, doc. no. R41129, available from https://opencrs.com/document/R41129/.

7 U.S. Dept. of Energy, Fiscal Year 2014 Stockpile Stewardship and Management Plan, Report to Congress, June 2013, Washington, DC, available from the website of the National Nuclear Security Administration, http://nnsa.energy.gov/sites/default/files/nnsa/06-13-inlinefiles/FY14SSMP_2.pdf.

8 The Nuclear Posture Review Report, April 2010, available from the U.S. Department of Defense website, http://www.defense.gov/npr/docs/2010\%20nuclear\%20posture\%20review\%20report.pdf.

9 NATO, Strategic Concept for the Defence and Security of the Members of the North Atlantic Treaty Organization, Adopted by Heads of State and Government at the NATO Summit in Lisbon 19-20 November 2010, available from the NATO website, http://www.nato.int/strategicconcept/pdf/Strat_Concept_web_en.pdf.

10 Australian Department of Defence, Defence White Paper 2013, available from the website of the Australian Department of Defence, http://www.defence.gov.au/whitepaper2013/docs/WP_2013_web.pdf.

11 RIA Novosti, Nuclear Arms Reduction Deals to Become Multilateral - Lavrov, June 22, 2013, available at http://en.ria.ru/world/20130622/181811968/Nuclear-Arms-Reduction-Deals-to-Become-Multilateral-Lavrov.html.

12 Shehzad Qazi, US-Pakistan Relations: Common and Clashing Interests, World Affairs, May/June 2012, available from the World Affairs website, http://www.worldaffairsjournal.org/article/us-pakistanrelations-common-and-clashing-interests.

13 Reuters News Service, US should dump Islamabad, Pakistan diplomat says, March 19, 2013, available from the Times of India website, http://articles.timesofindia.indiatimes.com/2013-0319/us/37843363_1_islamabad-pakistani-officials-pakistani-leaders.

14 Center for Security Studies (CSS), India-US Relations: Progress Amidst Limited Convergence, ETH Zurich 1, CSS Analysis in Security Policy, No. 117 • July 2012, available from the CSS website, http://www.css.ethz.ch/publications/pdfs/css_analysen_nr117_e.pdf. 
15 See, for example, Olga Bozheva, The Son of Satan Will Break through the American Missile-Defense, Moskovskiy Komsomolets, 20 October 2012 (online, at http://mk.ru, in Russian).

16 Office of the Secretary of Defense, Annual Report to Congress: Military and Security Developments Involving the People's Republic of China 2013, available from the Department of Defense website, http://www.defense.gov/pubs/2013_China_Report_FINAL.pdf.

17 Warheads, website of the Commissariat à l'énergie atomique (CEA), http://www.cea.fr/lecea/presentation-generale.

18 Presented to Parliament by the Secretary of State for Defence and the Secretary of State for Foreign and Commonwealth Affairs by Command of Her Majesty, The Future of the United Kingdom's Nuclear Deterrent, December 2006, doc. no. Cm 6994.

19 Thomas C. Schelling, The Strategy of Conflict (Harvard University, Cambridge, MA, 1960, 1980), p. 9.

20 Keith B. Payne, Testimony to the Energy and Water Development Subcommittee of the U.S. Senate Appropriations Committee, hearings on "Examining the proper size of the nuclear weapons stockpile to maintain a credible U.S. deterrent,” July 25, 2012.

21 Dana J. Johnson, Christopher J. Bowie, and Robert P. Haffa, Triad, Dyad, Monad? Shaping the U.S. Nuclear Force for the Future, Mitchell Paper 5, Mitchell Institute for Airpower Studies, December 2009, available from http://www.afa.org/mitchell/reports/MP5_Triad_1209.pdf.

22 Amy Woolf, U.S. Strategic Nuclear Forces: Background, Developments, and Issues, Congressional Research Service, January 14, 2013, doc. no. RL33540, available from http://www.crs.gov.

23 See The Nuclear Planning Group, on the NATO official website, http://www.nato.int/cps/en/natolive/topics_50069.htm.

24 US flies B-52s over South Korea amid North rhetoric, March 19, 2013, online BBC News Asia, http://www.bbc.co.uk/news/world-asia-21840215.

25 Thom Shanker and Choe Sang-hun, U.S. Runs Practice Sortie in South Korea, March, 28 2013, available from The New York Times online, http://www.nytimes.com/2013/03/29/world/asia/us-begins-stealthbombing-runs-over-south-korea.html.

26 See Deterrence Operations Joint Operating Concept, version 2.0, December 2006, available from http://www.dtic.mil/futurejointwarfare/joc.htm. 